\section{Polishing of Ground Y-TZP Ceramic is Mandatory for Improving the Mechanical Behavior}

\author{
Camila Pauleski Zucuni ${ }^{1}$, Luis Felipe Guilardi ${ }^{1}{ }^{2}$, Marilia Pivetta Rippe ${ }^{1}$, Gabriel \\ Kalil Rocha Pereira ${ }^{1,3}$, Luiz Felipe Valandro ${ }^{1}$
}

'Graduate Program in Oral Science, Prosthodontics Units, UFSM Universidade Federal de Santa Maria, Santa Maria, RS, Brazil ${ }^{2}$ Department of Dental Material Sciences, Academic Centre for Dentistry Amsterdam (ACTA), Universiteit van Amsterdam and Vrije Universiteit, Amsterdam,

The Netherlands

${ }^{3}$ Graduate Program in Dentistry, School of Dentistry, IMED - Faculdade Meridional, Passo Fundo, RS, Brazil

Correspondence: Luiz Felipe Valandro, Rua Floriano Peixoto, 1184, 97015-372, Santa Maria, RS, Brazil. Tel.: +55-55-3220-9276. e-mail: Ifvalandro@hotmail.com

\begin{abstract}
Key Words: Dental ceramics, zirconium oxide partially stabilized by yttrium, glazing, annealing, grinding.
\end{abstract}

\section{Introduction}

All-ceramic restorations have been widely used due to their superior aesthetics and biocompatibility when compared to the conventional metal-ceramics (1). Considering the existing ceramics, yttrium-stabilized tetragonal zirconia polycrystal (Y-TZP) has been noted for its high strength and fracture toughness, and has been recommended for manufacturing prosthetic frameworks of fixed dental prosthesis (FDPs), which are then veneered by a feldspathic porcelain, as well as for full-contour monolithic restorations, where veneering is not necessary (2).

Y-TZP is a polymorphic metastable material (3) that in response to different stimuli (e.g. stress concentration or exposure to environment with humidity) may undergo a phase transformation mechanism (tetragonal $-t$ to monoclinic $-m$ ). This transformation results in a restricted volumetric expansion around the defects creating a compressive stress layer at the crack origin that counteracts the crack propagation, a mechanism widely known as transformation toughening mechanism (1).

However, the surface roughness increases as the phase transformation mechanism progresses, first on surface grains with the incorporation of water in the open spaces and then spreading to the subsurface. This increase in surface roughness leads to a decrease in hardness, fracture toughness and density of zirconia, a process known as low-temperature degradation - LTD (4).

It is important to consider that clinical adjustments (e.g., grinding with diamond instruments) are usually needed to achieve a better fit, create an adequate emergency profile, or improve the occlusal relations for both recommended restorative applications for Y-TZP ceramics (FDPs' frameworks or full-contour monolithic restorations), after its manufacturing, by CAD/CAM system (Computer-Aided Design / Computer-Aided Manufacturing), and sintering processes (5).

Thus, when the Y-TZP surface is ground, clinicians need to be aware that surface defects are introduced and $m$-phase content will appear (6). The relation between the size of the resulting defects/cracks and the depth of the transformed layer determines the crack growth, consequently whether the material will fail at loads below its normal critical load value (7).

After grinding, manufacturers usually recommend a polishing protocol, which should be executed to achieve a smooth and shining surface (5); and/or a glazing procedure on the surface again to promote a smooth and shining surface (8); and/or a heat treatment/annealing, that consists 
to subject the zirconia to a specific heat treatment, with temperatures around $1000{ }^{\circ} \mathrm{C}$ for $15 \mathrm{~min}$, aiming for the complete reversion of $m$ to $t$ phase (9).

However, until now, there is no evidence showing the zirconia's susceptibility to the aging process after the execution of different surface treatments (polishing, glaze and heat treatment) and as they promote phase transformation and interacts with the material's surface, it could be expected an influence of these factors on the aging kinetics of Y-TZP ceramics. Thus, this study evaluated and compared the effect of aging on the surface characteristics (micromorphology and roughness), structural stability (phase transformation) and mechanical behavior (flexural strength and structural reliability - Weibull analysis), after the execution of different surface treatments of a ground Y-TZP ceramic. The null hypothesis is that different surface treatments will not affect the aging of the Y-TZP ceramic.

\section{Materials and Methods}

\section{Specimen Preparation}

Disc shaped ( $\mathrm{N}=300$ discs -10 groups of 30 samples) specimens $(15 \mathrm{~mm}$ in diameter and $1.2 \pm 0.2 \mathrm{~mm}$ in thickness) were manufactured from Y-TZP ceramic blocks (VITA In-Ceram YZ for inLab YZ-40/19, 40×19×15 mm³, ₹ VITA Zahnfabrik, Bad Sackingen, Germany), according to the ISO:6872-2015 (10) guidelines for ceramic biaxial flexure strength testing.

The ceramic blocks were detached from the metal holder and cylindrical metal rings of $18 \mathrm{~mm}$ were fixed in both sides of the block. The block was then ground using 600 grit silicon carbide papers in a polishing machine (EcoMet/ AutoMet 250, Buehler, Lake Bluff, USA) until a cylindrical shape was achieved. The cylinders were then sliced in a saw machine (ISOMET 1000, Buehler) with a diamond disc (Extec Diamond Wafering Blade, Extec, Enfield, USA) under water irrigation, polished with 1200 grit silicon carbide paper and sintered according to the manufacturer's recommendations (Zyrcomat T, Vita Zahnfabrik).

Immediately after sintering, all specimens had their dimensions inspected with a digital caliper (Mitutoyo, Absolute 500-196-20 Digital Caliper, Takatsu-ku, Kawasaki, Kanagawa, Japan) to guarantee that they presented values inside the range recommended by the IS0:6872-2015 (10)for ceramic biaxial flexure strength testing (diameter of 12 to 16 $\mathrm{mm}$; thickness of $1.2 \pm 0.2 \mathrm{~mm}$ ). The samples were cleaned in an ultrasonic bath (1440 D - Odontobras, Ind. E Com. Equip. Méd. Odonto. LTDA, Ribeirao Preto, SP, Brazil) using $78 \%$ isopropyl alcohol for $5 \mathrm{~min}$, and randomly allocated to ten groups according to the study factors (Table 1).

\section{Surface Treatments}

Samples from the control group (Ctrl) remained untouched after the sintering process - "as- sintered" samples.

\section{Grinding}

Grinding was performed by a single trained operator using diamond burs (\#3101G - grit size 181 нm; KG Sorensen, Cotia, SP, Brazil) in a slow-speed motor (Kavo Dental, Biberach, Germany) coupled to a contra-angle handpiece (T2 REVO R170 contra-angle handpiece up to 170,000 rpm, Sirona, Bensheim, Germany) under constant water-cooling $(\approx 30 \mathrm{~mL} / \mathrm{min})$. Samples were attached to a device that guaranteed the parallelism between the surface to be ground and the diamond bur. For standardization of the wear thickness and to guarantee that the entire surface was ground, the specimens were marked with a permanent marking pen (Pilot, São Paulo, Brazil). Then, the grinding procedure was performed manually, using oscillatory movements, up to the point that the marking was completely eliminated. The diamond bur was replaced after each specimen (11).

\section{Polishing}

Polishing was executed using the Eve Diapol ceramic polishing kit (Eve Ernst Vetter, Pforzheim, Germany), which uses rubber tips in three granulations (blue - coarse grit size; pink - medium grit size; grey - fine grit-size), coupled to an electric motor (W\&H Perfecta 300, W\&H Dentalwerk, Bürmoos, Austria) that allows control of speed $(12,000 \mathrm{rpm})$. A device was used to guarantee the parallelism between the specimen and the polishing tips.

In order to standardize the polishing time, each specimen was divided into 7 regions (considering the size of the rubber tip) and then polishing was executed moving the tip forward and backwards (whole specimen extension) for 7 seconds in each region of the specimen (total of 49 seconds for each tip per specimen).

Table 1. Experimental design

\begin{tabular}{|c|c|c|}
\hline Surface treatment & LTD & Groups' Codes \\
\hline $\begin{array}{l}\text { As-sintered } \\
\text { (without treatment, control) }\end{array}$ & $\begin{array}{l}\text { Without } \\
\text { With }\end{array}$ & $\begin{array}{c}\text { Ctrl } \\
\text { Ctrl + Aut }\end{array}$ \\
\hline $\begin{array}{l}\text { Grinding with Coarse Diamond Bur } \\
\text { \#3101G (average grit size } 181 \mu \mathrm{m} \text { ) }\end{array}$ & $\begin{array}{l}\text { Without } \\
\text { With }\end{array}$ & $\begin{array}{c}\mathrm{Gr} \\
\mathrm{Gr}+\mathrm{Aut}\end{array}$ \\
\hline $\begin{array}{l}\text { Grinding with Coarse Diamond } \\
\text { Bur \#3101G (average grit size } \\
181 \mu \mathrm{m})+ \text { Heat treatment }\end{array}$ & $\begin{array}{l}\text { Without } \\
\text { With }\end{array}$ & $\begin{array}{c}\mathrm{Gr}+\mathrm{HT} \\
\mathrm{Gr}+\mathrm{HT}+\mathrm{Aut}\end{array}$ \\
\hline $\begin{array}{l}\text { Grinding with Coarse Diamond } \\
\text { Bur \# } 3101 \mathrm{G} \text { (average grit } \\
\text { size } 181 \mu \mathrm{m} \text { ) + Polishing }\end{array}$ & $\begin{array}{l}\text { Without } \\
\text { With }\end{array}$ & $\begin{array}{c}\mathrm{Gr}+\mathrm{Pol} \\
\mathrm{Gr}+\mathrm{Pol}+\mathrm{Aut}\end{array}$ \\
\hline $\begin{array}{l}\text { Grinding with Coarse Diamond } \\
\text { Bur \#3101G (average grit } \\
\text { size } 181 \mu \mathrm{m})+ \text { Glazing }\end{array}$ & $\begin{array}{l}\text { Without } \\
\text { With }\end{array}$ & $\begin{array}{c}\mathrm{Gr}+\mathrm{Gl} \\
\mathrm{Gr}+\mathrm{Gl}+\mathrm{Aut}\end{array}$ \\
\hline
\end{tabular}




\section{Heat treatment/Annealing}

The heat treatment/annealing was executed as recommended by the manufacturers using a Vacumat $6000 \mathrm{MP}$ furnace (Vita Zahnfabrik): initial temperature of $500^{\circ} \mathrm{C}$, heating time of $5 \mathrm{~min}$, heating rate of $100^{\circ} \mathrm{C} / \mathrm{min}$, and maintenance of the final temperature of $1000^{\circ} \mathrm{C}$ for 15 min.

\section{Glazing}

A thin layer of glaze material (Vita Akzent, Vita Zahnfabrik) was applied to the ground surface, following the manufacturer's instructions. The powder was mixed with distilled water until a homogeneous paste was achieved. The paste was then applied to the surface using a specific brush. After drying, the specimens were submitted to glaze firing in the Vacumat 6000MP furnace (Vita Zahnfabrik): initial temperature of $500^{\circ} \mathrm{C}$ for $4 \mathrm{~min}$, heating rate of $80^{\circ} \mathrm{C} / \mathrm{min}$, and maintaining the final temperature of $900^{\circ} \mathrm{C}$ for $1 \mathrm{~min}$.

\section{Aging}

Low-Temperature Degradation (LTD) was simulated in half of the samples of each surface treated condition using an autoclave (Sercon HS1-0300 n11560389/1, Mogi das Cruzes, Brazil) at $134^{\circ} \mathrm{C}$, under a 2 bar pressure, over a period of $20 \mathrm{~h}(6,12)$.

\section{Surface Topography and Roughness Analysis}

For the qualitative and quantitative determination of the surface topography pattern for each evaluated condition, specimens were analyzed in a surface roughness tester ( $n=30$, Mitutoyo SJ-410, Mitutoyo), scanning electron microscope (SEM) ( $n=2$, FE-SEM Inspect F50, FEl, Hillsboro, Oregon, USA), and atomic force microscope (AFM) $(n=2$, Agilent Technologies 5500 equipment, Chandler, Arizona, USA).

For surface roughness analysis, three measurements (measured range up to $80 \mu \mathrm{m}$ with an expected accuracy of $0.001 \mu \mathrm{m}$ ) were conducted for each specimen, according to the parameters $\mathrm{Ra}$ and $\mathrm{Rz}$ ( $\mathrm{Ra}$ - arithmetical mean of the absolute values of peaks and valleys measured from a medium plane $(\mu \mathrm{m})$ and $\mathrm{Rz}$ - average distance between the five highest peaks and five major valleys found in the standard $(\mu \mathrm{m})$ ), with a cut-off of $5, \lambda \mathrm{C}$ of $0.8 \mathrm{~mm}$ and $\lambda$ Sof $2.5 \mu \mathrm{m}$. Arithmetic mean values of all measurements from each specimen were obtained.

For scanning electron microscopy, two specimens from each group were submitted to sputter-coating with a goldpalladium alloy and images were obtained at a 5000x of magnification.

For atomic force microscopy, two specimens from each group were submitted to the analysis and the data were obtained using a non-contact methodology with specific probes measuring an area of a $10 \times 10 \mu \mathrm{m}$ (PPP-NCL probes, Nanosensors; Force constant $=48 \mathrm{~N} / \mathrm{m}$ ). The images were obtained using specific computer software (Gwyddion ${ }^{\text {TM }}$ version 2.33, GNU, Free Software Foundation, Boston, MA, USA).

Prior to the surface topography analysis, all specimens were cleaned in an ultrasonic bath as described previously.

\section{Phase analysis (X-Ray Diffractometry - XRD)}

Quantitative analysis of phase transformation was conducted $(n=2)$ to determine the relative amount of $m$-phase and depth of the transformed layer for each condition. The analysis was performed using an x-ray diffractometer (Bruker AXS, D8 Advance, Karlsruhe, Germany). Spectra were collected in the $2 \theta$ range of $25^{\circ}-35^{\circ}$ at a step interval of $1 \mathrm{~s}$ and step size of $0.03^{\circ}$. The amount of $m$-phase $\left(X_{M}\right)$ was calculated using the method developed by Garvie and Nicholson (13):

$$
X m=\frac{(\overline{1} 11) M+(111) M}{(\overline{1} 11) M+(111) M+(111) T}
$$

where: $(\overline{111})_{M}$ and $(111)_{M}$ represent the monoclinic peaks $\left(2 \theta=28^{\circ}\right.$ and $2 \theta=31.2^{\circ}$, respectively) and $(111)_{T}$ indicates the intensity of the respective tetragonal peak $\left(2 \theta=30^{\circ}\right)$. The volumetric fraction $\left(F_{m}\right)$ of the $m$-phase was calculated according to Toraya et al. (14):

$$
F m=\frac{1.311 \cdot \mathrm{Xm}}{1+0.311 \cdot \mathrm{Xm}}
$$

The depth of the transformed layer (TZD) was calculated on the basis of the amount of the $m$-phase, considering that a constant fraction of grains had symmetrically transformed to $\mathrm{m}$-phase along the surface, as described by Kosmac et al. (15):

$$
T Z D=\left(\frac{\operatorname{sen} \theta}{2 \mu}\right)\left[\operatorname{In}\left(\frac{1}{1-F m}\right)\right]
$$

where $\theta=15^{\circ}$ (the angle of reflection), $\mu=0.0642$ is the absorption coefficient, and $\mathrm{F}_{\mathrm{M}}$ is the amount of $m$-phase obtained using Eqs. (1) and (2).

\section{Biaxial Flexure Strength Test}

A single trained operator performed the biaxial flexure strength test. Samples $(n=30)(11)$ were subjected to the test according to ISO:6872-2015 (10). Disc-shaped specimens were positioned with the treated surface facing down 
(tensile stress) on three supporting balls $(\emptyset=3.2 \mathrm{~mm})$, which were placed $10 \mathrm{~mm}$ apart from each other in a triangular position. The assembly was immersed in water and a flat circular tungsten piston ( $\emptyset=1.6 \mathrm{~mm}$ ) was used to apply an increasing load (1 $\mathrm{mm} / \mathrm{min})$ until catastrophic failure using a universal testing machine (EMIC DL 2000, São José dos Pinhais, PR, Brazil). Before testing, an adhesive tape was fixed on the compression side of the discs to avoid spreading the fragments (16) and also to provide better contact between the piston and the sample (17). Flexural strength was calculated according to the IS0:6872-2015 (10):

$$
\sigma=-0.2387 \cdot \frac{p(X-Y)}{b^{2}}
$$

where $\sigma$ is the maximum tensile stress ( $\mathrm{MPa}), \mathrm{P}$ is the total load to fracture $(\mathrm{N}), \mathrm{b}$ is the thickness at fracture origin $(\mathrm{mm})$, and $X$ and $Y$ are calculated according to:

$$
X=(1+v) \ln \left(\frac{r_{2}}{r_{3}}\right)^{2}+\left[\frac{(1-v)}{2}\right]\left(\frac{r_{2}}{r_{3}}\right)^{2}
$$

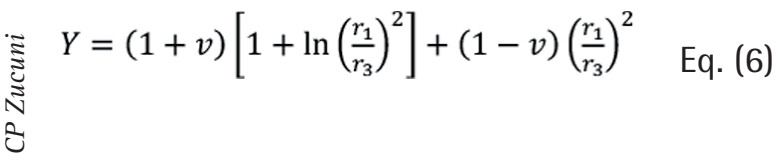

where $v$ is Poisson's ratio $(v=0.25), r_{1}$ is the radius of the support circle $(5 \mathrm{~mm}), r_{2}$ is the radius of the loaded area $(0.8 \mathrm{~mm})$, and $r_{3}$ is the radius of the specimen $(7.5 \mathrm{~mm})$.

\section{Data Analysis}

As roughness data ( $R$ a and $R z$ ) assumed a nonparametric distribution (tested by Shapiro-Wilk normality test), Kruskal-Wallis and the post-hoc Dunn's tests were performed. In addition, the Spearman Correlation test between the $\mathrm{Ra}$ and $\mathrm{Rz}$ roughness data and biaxial flexure strength data were performed.

The statistic used to describe the reliability of the ceramic material was based on the Weibull statistical analysis (18), which is a way to describe the variation of strength obtaining the Weibull modulus $(\mathrm{m})$ and the characteristic strength $(\sigma c)$ with a confidence interval of $95 \%$, as determined in a diagram according to DIN ENV 843-5(19):

$$
\ln \ln \left(\frac{1}{1-F}\right)=m \ln \sigma_{c}-m \ln \sigma_{0}
$$

where $F$ is the failure probability, $\sigma_{0}$ is the initial strength, $\sigma_{\mathrm{c}}$ is the characteristic strength, and $\mathrm{m}$ is the Weibull modulus. The characteristic strength is the strength at a failure probability of approximately $63 \%$, with the Weibull modulus used as a measure of the distribution of strengths, expressing the reliability of the material.

\section{Fractography Analysis}

A fractography examination was performed using a light microscope (Stereo Discovery V20; Carl Zeiss, Gottingen, Germany), where representative specimens for each evaluated condition were chosen and submitted to further evaluation in a SEM to determine the origin of the fracture.

Additional SEM analysis $(n=5)$ was made on fractured specimens to check the mean average thickness of the glaze layer.

\section{Results}

SEM and AFM analysis showed that grinding produces a more irregular surface, introducing scratches following the direction of the grinding movement. Heat treatment did not promote any noticeable topographical alteration, resulting in a surface that was similar to the ground samples. Polishing and glazing result in a more regular surface, demonstrating its smoothening potential. Aging did not promote any relevant effect on topography (Fig. 1).

Roughness analysis ( $\mathrm{Ra}$ and $\mathrm{Rz}$ parameters) showed that there was a statistically significant increase in roughness after grinding; heat treatment/annealing did not affect surface roughness, while polishing and glazing lead to a decrease in roughness when compared to the ground condition. However, polishing and glazing did not re-establish the roughness observed in the as-sintered condition (Ctrl). Generally, aging did not affect the surface roughness; nevertheless, ground aged specimens demonstrated smaller roughness values (Table 2 ).

The Spearman correlation test between roughness ( $R a$ and Rz parameters) and biaxial flexure strength parameters demonstrated coefficient values lower than $0.4(0.0<$ (r) $<0.4$ ), depicting a very weak correlation (Table 2 ).

The grinding led to an increase in m-phase content, which was reverted in a small scale under polishing and glazing, and was completely reverted under heat treatment/ annealing. Aging led to an intense increase in $\mathrm{m}$-phase content under all evaluated conditions, although different susceptibilities to $\mathrm{t}-\mathrm{m}$ phase transformation were observed (Table 2).

Weibull analysis demonstrated higher characteristic strength values for ground and ground + polished conditions and decreased characteristic strength for heat treatment and glazing. Aging in an autoclave promoted no deleterious effect for structural reliability (Weibull moduli) (Table 2).

Fractography analysis showed that the fracture started 
at the superficial defects on the side subjected to tensile stress (treated surface) at the center region of all specimens; with the exception for the glaze group where the fractures originated from the interface between the glaze and Y-TZP on the same previously described region (Fig. 2).

\section{Discussion}

Based on our results, considering the different Y-TZP
SEM images
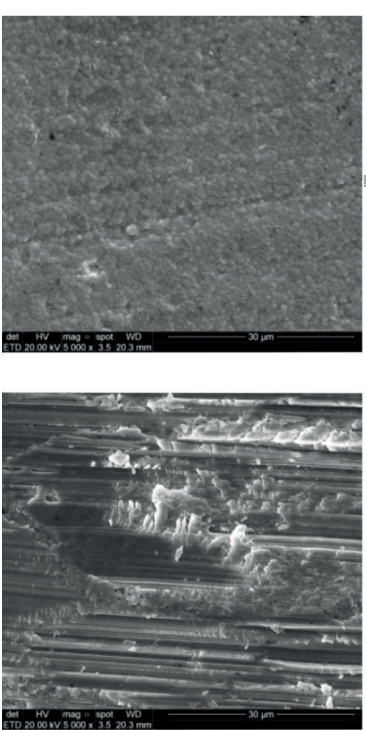

Gr

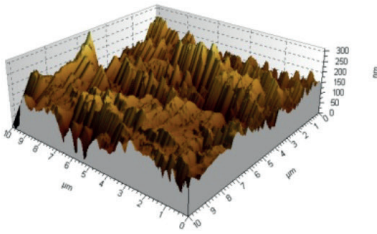

$\mathbf{G r}+\mathbf{H t}$
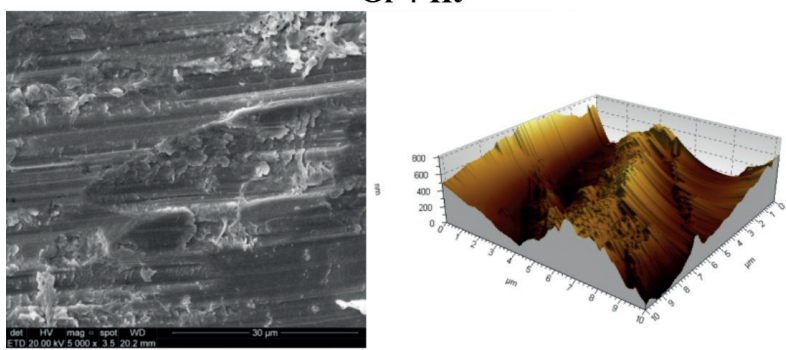

Gr + Pol
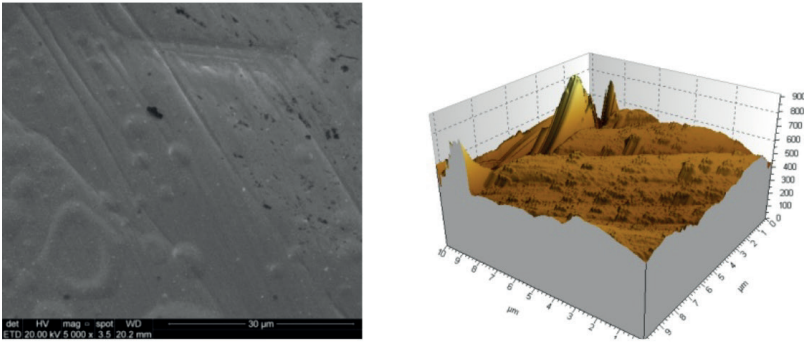

$\mathbf{G r}+\mathbf{G l}$
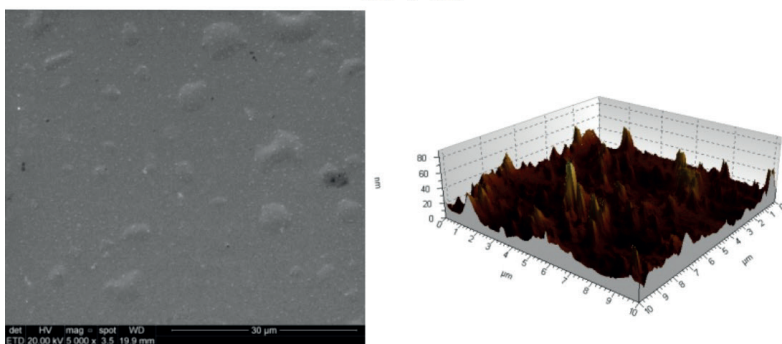

SEM images

AFM images

Ctrl + Aut
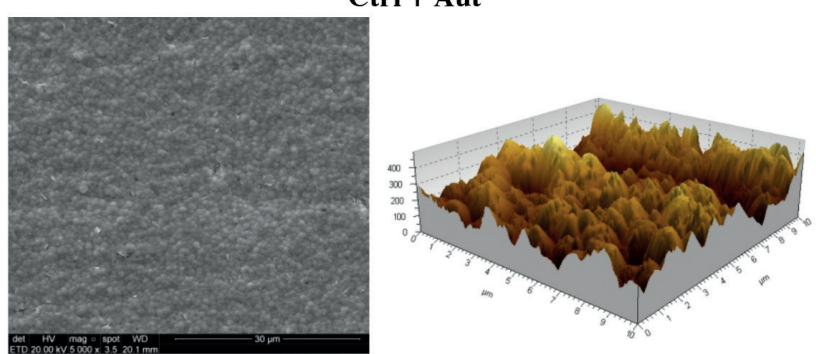

Gr + Aut

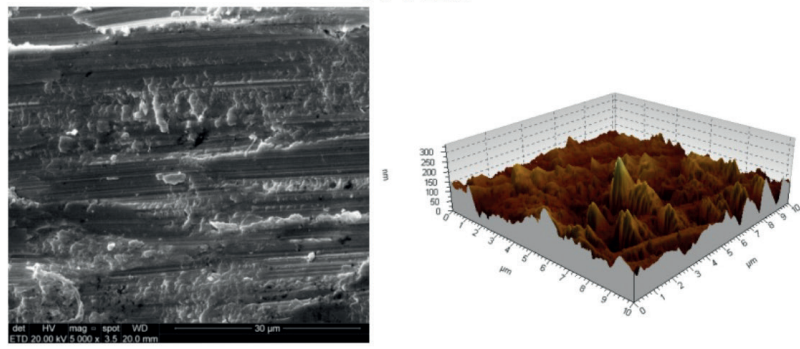

$\mathbf{G r}+\mathbf{H t}+\mathbf{A u t}$
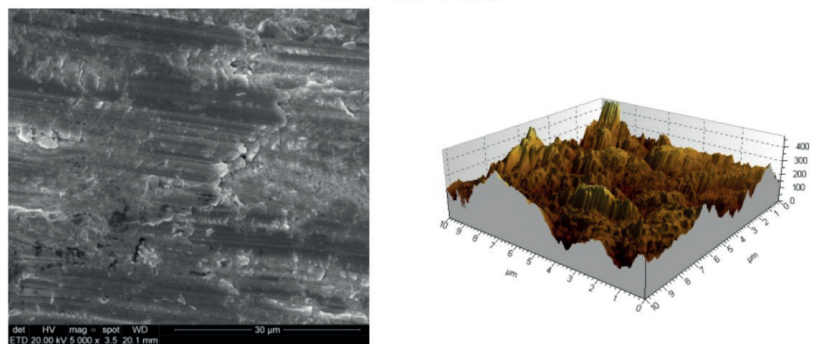

Gr + Pol + Aut
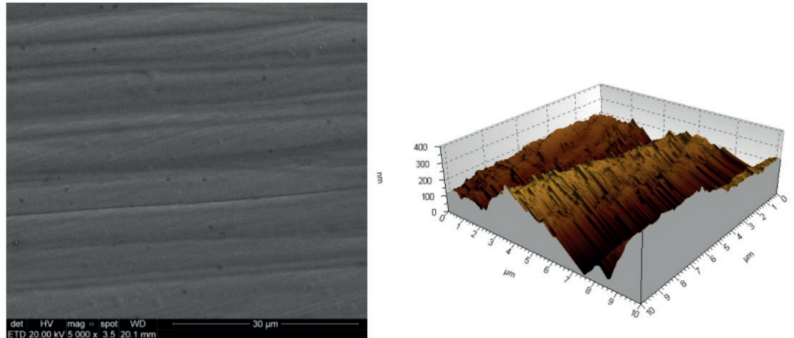

Gr + Gl + Aut
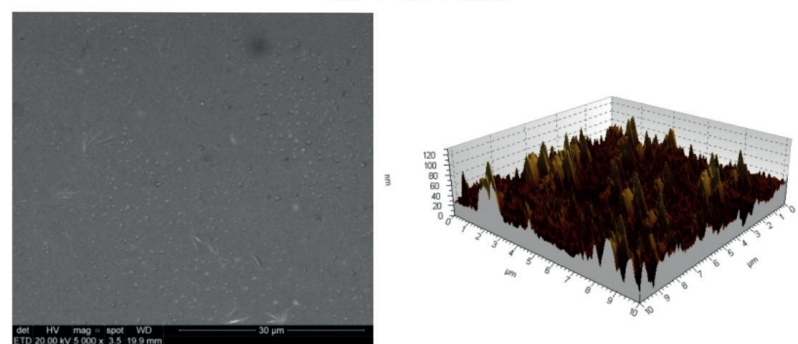

Figure 1. Representative SEM images (5000× magnification) and AFM images (20 $\mu \mathrm{m} \times 20 \mu \mathrm{m})$ of Y-TZP surface for different conditions, demonstrating that grinding with diamond burs (Coarse) modified the topographic pattern of "as sintered" samples creating parallel scratches following the movement of the grinding tool and deforming the surface. Heat treatment did not promote any change on those aspects, while polishing and glazing successfully demonstrate a smoothening potential. Aging cause none relevant alteration for any evaluated condition. 
conditions (as-sintered, ground, ground + post-processing treatments), it was depicted different susceptibilities to aging. In this sense, the polishing and glazed conditions demonstrated the lowest susceptibility to $t-m$ phase transformation during aging in autoclave. In addition, polishing promotes a decrease in roughness (smoother topography), provides the highest characteristic strength.

Thus, it seems that one factor that may influence the susceptibility to aging of the Y- TZP ceramic (20) is its surface roughness; which is in accordance to Dutra et al. (12), where different surface roughness influenced the surface free-energy leading to the hypothesis that in a smoother surface the contact area with water is smaller, and by that it reduces the potential of aging coming from this interaction.

In this sense, smooth surfaces of ceramic restorations are mandatory in order to reduce the amount of plaque formation (21), secondary caries occurrence, besides a decreased wear of the antagonist tooth, improving the longevity of restorations (5). Thus, in addition to our findings, it becomes clear the necessity of executing a polishing protocol after the adjustment of Y-TZP restorations to provide a smoother and homogenous surface, enhancing its mechanical behavior, clinical performance and decreasing its susceptibility to aging (22).
Our findings show that an increase in $m$-phase content led to higher characteristic strength (transformation toughening mechanism), which is corroborated by the literature (11). Even when $60 \%$ of $m$-phase content is observed (Ctrl + Aut), an increased characteristic strength was noticed. However, this outcome may change when the Y-TZP surface is ground, since the grinding + aging condition demonstrated a decrease in strength, even though it presented a smaller $m$-phase content (approximately 40\%) when compared to the Ctrl + Aut group. This fact points out that the defects introduced by grinding may become deleterious when associated with aging (even with an increase in $m$-phase content), which confirms the previous findings of Pereira et al. (6).

In regards of the effect of heat treatment, it was noticed a decrease on the characteristic strength of the material, which may be explained by the phase reversion $(\mathrm{m}-\mathrm{t})$, consequently the toughening mechanism is reverted and the defects introduced into the material remained to propagate under stress concentration (9). Additionally, for the glaze group $(\mathrm{Gr}+\mathrm{Gl})$, it depicted a reduced characteristic strength, which can be associated with the increased incompatibility between these materials (weak adhesion between zirconia and glaze) (2). Besides, Pozzobon et al. (26) demonstrated that the strength of a bilayer material

Table 2. Roughness analysis (parameter Ra and Rz), Spearman Correlation, X-ray Difractometry analysis (\% of monoclinic phase and depth of transformed layer), Weibull modulus $(m)$, Characteristic strength $\left(\sigma_{c}\right)$ and respective confidence intervals (CI $\left.-95 \%\right)$.

\begin{tabular}{|c|c|c|c|c|c|c|c|c|}
\hline \multirow[b]{2}{*}{ Groups } & \multicolumn{2}{|c|}{ Roughness Analysis } & \multicolumn{2}{|c|}{ Spearman Correlation } & \multicolumn{2}{|c|}{ XRD Analysis } & \multicolumn{2}{|c|}{ Weibull Analysis } \\
\hline & $\mathrm{Ra}(\mu \mathrm{m})$ & $\mathrm{Rz}(\mu \mathrm{m})$ & $(\sigma \times \mathrm{Ra})$ & $(\sigma \times \mathrm{Rz})$ & $\begin{array}{l}\text { m-phase } \\
\text { content } \\
(\%)\end{array}$ & $\begin{array}{l}\text { TZD } \\
(\mu \mathrm{m})\end{array}$ & $m$ (CI 95\%) & $\sigma_{\mathrm{c}}(\mathrm{CI} 95 \%)$ \\
\hline Ctrl & $0.24 \pm 0.83^{\mathrm{A}}$ & $1.93 \pm 0.50^{\mathrm{A}}$ & $-0.239(p=0.203)$ & $-0.349(\mathrm{p}=0.059)$ & 1.4 & 0.1 & $9.7(6.8-12.5)^{\mathrm{AB}}$ & $\begin{array}{c}964.7 \\
(922.5-1007.5)^{\mathrm{D}}\end{array}$ \\
\hline $\begin{array}{l}\text { Ctrl } \\
+ \text { Aut }\end{array}$ & $0.21 \pm 0.34^{\mathrm{A}}$ & $1.77 \pm 0.36^{\mathrm{A}}$ & $0.018(\mathrm{p}=0.926)$ & $-0.193(\mathrm{p}=0.306)$ & 65.6 & 5.4 & $26.0(18.2-33.4)^{\mathrm{C}}$ & $\begin{array}{c}1030.3 \\
(1013.2-1047.3)^{E}\end{array}$ \\
\hline Gr & $1.55 \pm 0.65^{\mathrm{D}}$ & $8.26 \pm 1.26^{\mathrm{D}}$ & $0.029(p=0.880)$ & $-0.166(p=0.381)$ & 13.9 & 0.8 & $10.7(7.5-13.7)^{\mathrm{AB}}$ & $\begin{array}{c}1183.3 \\
(1136.0-1231.3)^{\mathrm{G}}\end{array}$ \\
\hline $\mathrm{Gr}+\mathrm{Aut}$ & $1.33 \pm 0.12^{\mathrm{C}}$ & $8.09 \pm 0.89^{\mathrm{D}}$ & $0.086(p=0.653)$ & $0.037(\mathrm{p}=0.845)$ & 43.2 & 2.9 & $14.0(9.8-18.0)^{\mathrm{B}}$ & $\begin{array}{c}1085.7 \\
(1052.5-1118.9)^{\mathrm{F}}\end{array}$ \\
\hline $\mathrm{Gr}+\mathrm{HT}$ & $1.35 \pm 0.15^{\mathrm{C}}$ & $8.33 \pm 0.98^{\mathrm{D}}$ & $-0.254(p=0.175)$ & $-0.399(\mathrm{p}=0.029)$ & 0 & 0.0 & $15.3(10.7-19.6)^{\mathrm{BC}}$ & $\begin{array}{c}818.5 \\
(795.4-841.3)^{\mathrm{B}}\end{array}$ \\
\hline $\begin{array}{l}\mathrm{Gr}+\mathrm{HT} \\
+ \text { Aut }\end{array}$ & $1.35 \pm 0.19^{\mathrm{C}}$ & $8.27 \pm 1.15^{\mathrm{D}}$ & $-0.081(p=0.671)$ & $-0.162(\mathrm{p}=0.392)$ & 26.6 & 1.6 & $29.2(20.5-37.6)^{\mathrm{C}}$ & $\begin{array}{c}882.0 \\
(869.0-894.8)^{\mathrm{C}}\end{array}$ \\
\hline Gr + Pol & $0.60 \pm 0.14^{\mathrm{B}}$ & $3.76 \pm 0.79^{C}$ & $-0.069(p=0.716)$ & $-0.089(\mathrm{p}=0.639)$ & 9.6 & 0.5 & $10.0(7.0-12.8)^{\mathrm{AB}}$ & $\begin{array}{c}1286.2 \\
(1231.2-1342.1)^{c}\end{array}$ \\
\hline $\begin{array}{l}\text { Gr + Pol } \\
+ \text { Aut }\end{array}$ & $0.53 \pm 0.12^{\mathrm{B}}$ & $3.16 \pm 0.60^{\mathrm{B}}$ & $0.185(\mathrm{p}=0.327)$ & $0.233(p=0.215)$ & 20.3 & 1.2 & $7.0(4.9-9.1)^{\mathrm{A}}$ & $\begin{array}{c}1309.3 \\
(1230.9-1390.4)^{c}\end{array}$ \\
\hline $\mathrm{Gr}+\mathrm{Gl}$ & $0.62 \pm 0.26^{\mathrm{B}}$ & $3.54 \pm 1.91^{\mathrm{C}}$ & $0.133(\mathrm{p}=0.482)$ & $0.122(\mathrm{p}=0.519)$ & 7.3 & 0.4 & $13.8(9.6-17.7)^{\mathrm{B}}$ & $\begin{array}{c}745.4 \\
(722.2-768.6)^{\mathrm{A}}\end{array}$ \\
\hline $\begin{array}{l}\mathrm{Gr}+\mathrm{Gl} \\
+ \text { Aut }\end{array}$ & $0.64 \pm 0.21^{\mathrm{B}}$ & $3.54 \pm 1.43^{\mathrm{C}}$ & $0.321(\mathrm{p}=0.083)$ & $0.259(\mathrm{p}=0.166)$ & 17.2 & 1.0 & $14.6(10.2-18.7)^{\mathrm{BC}}$ & $\begin{array}{c}732.1 \\
(710.6-753.7)^{\mathrm{A}}\end{array}$ \\
\hline
\end{tabular}

Same letters mean no statistically significant difference. Different letters correspond to statistical difference. 
(Y-TZP + glaze) was influenced by the material under tensile stress during the biaxial flexure test (i.e. the glaze). Thus, the

\section{Ctrl}
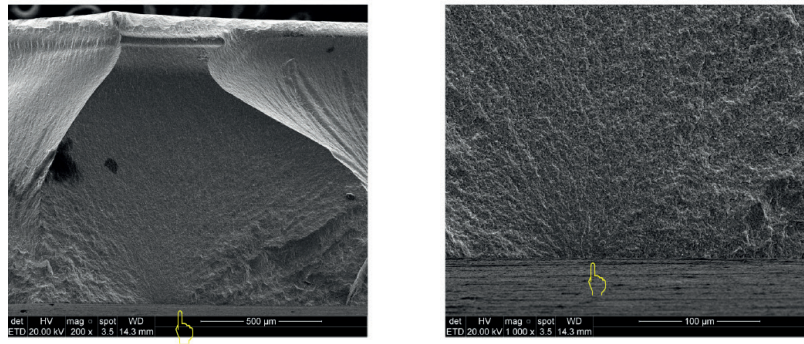

Gr
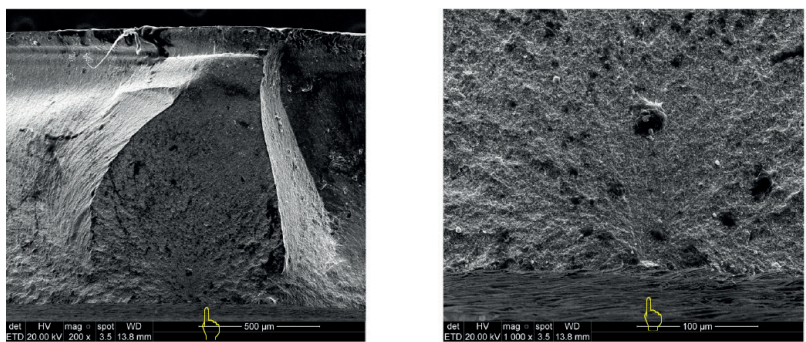

$\mathbf{G r}+\mathbf{H T}$
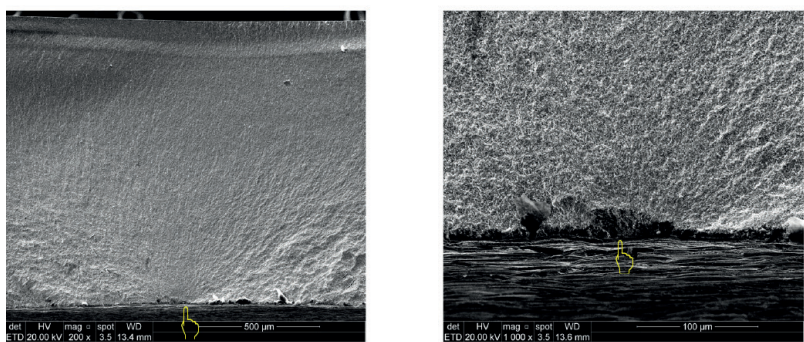

Gr + Pol
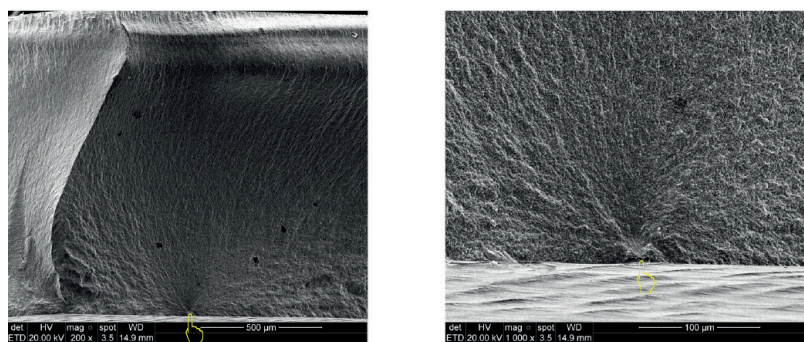

\section{$\mathbf{G r}+\mathbf{G l}$}
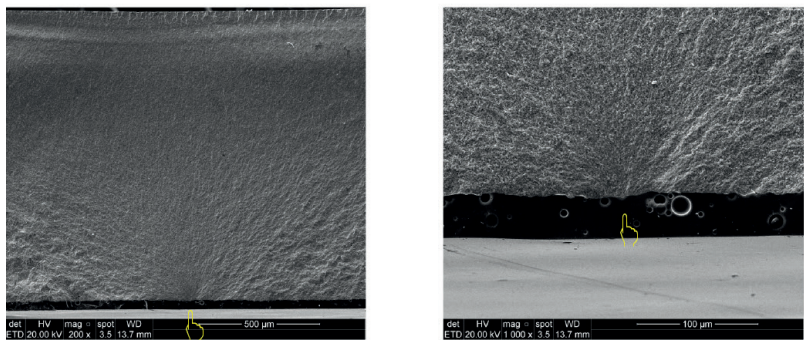

crack started from the surface (glaze) placed under tension stress and propagated into the material's core (Y-TZP).

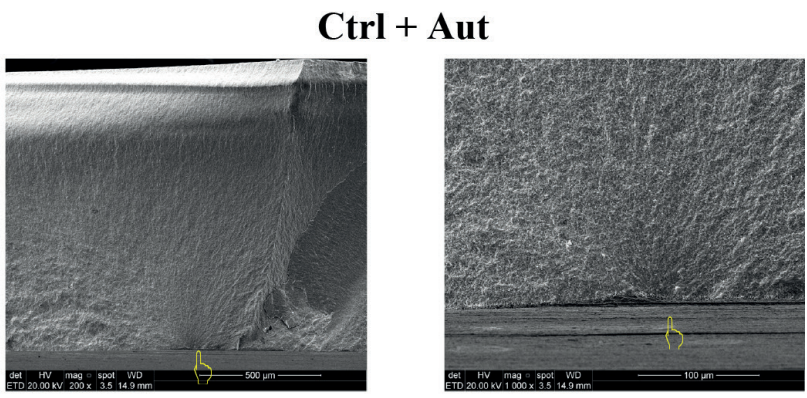

\section{Gr + Aut}

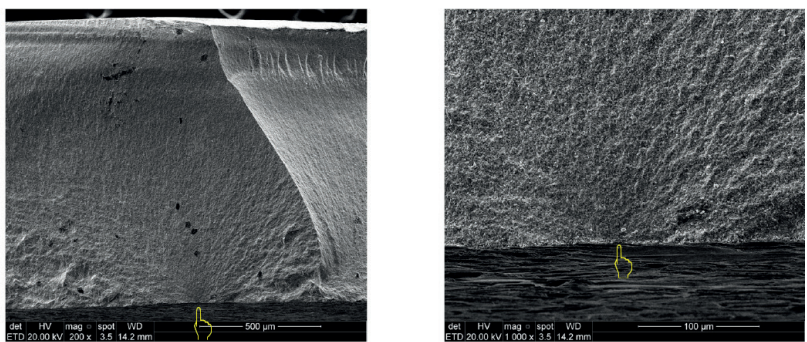

$\mathbf{G r}+\mathbf{H T}+\mathbf{A u t}$
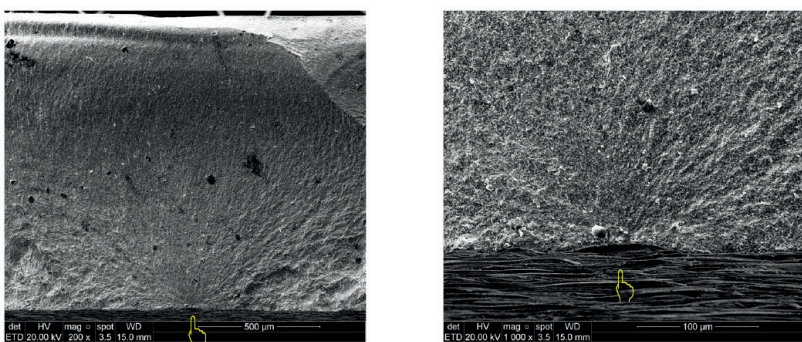

Gr + Pol + Aut

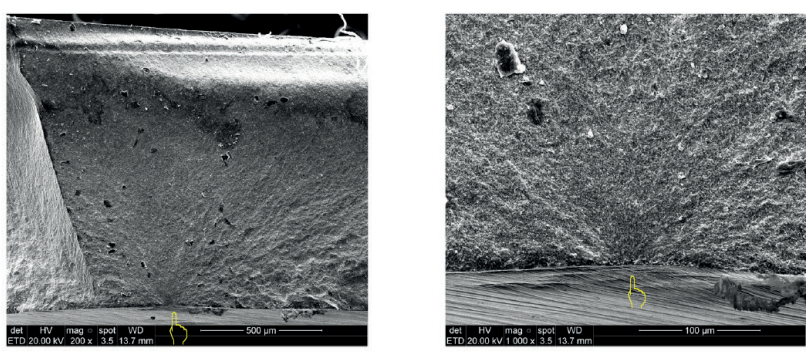

$\mathbf{G r}+\mathbf{G l}+\mathbf{A u t}$

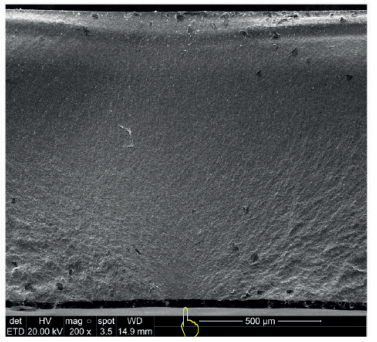

Figure 2. Representative images of the fractography analysis under SEM (200x and 1000x magnification): Typical brittle fracture surfaces, which clearly shows that the initial crack nucleation and propagation region are located in the lower side of the micrographs, corresponding to the region of maximum tensile stress in the biaxial test. For Ctrl, Gr, Gr $+\mathrm{Ht}$ (and respective aged conditions), it observes that the fracture originates on superficial defects; for $\mathrm{Gr}+\mathrm{Pol}$ (with and without aging), it starts on subsurface defects, while Gr + Gl (with and without aging) the fracture originates on the glaze/Y-TZP interface. The $b$ pointer indicates the fracture origin. 
At the same time, our study shows that grinding before aging decreases the susceptibility to $t-m$ phase transformation - this fact is more evident for postprocessing treatments (polishing, glazing and heat treatment/annealing) subjected to aging. Some studies show that grinding introduces compressive residual stresses at the surface decreasing its susceptibility to $t-m$ phase transformation $(7,23)$. Additionally, Muñoz-Tabares and Anglada (24) stated that the change in the superficial microstructure induced by grinding could play an important role on the susceptibility of $t-m$-phase transformation.

The grinding produces three main structural changes in the material. These changes start on the surface and then propagate to the inner: 1) a superficial crystallized zone, having grain diameter ranging from 10 to $20 \mathrm{~nm}$ approximately; 2) a plastically deformed zone; and 3 ) a zone where the tetragonal to monoclinic phase transformation takes place, which is responsible for the compressive tensions being associated to an increase of flexural strength and apparent fracture toughness of the ground ceramic (25).

We observed that heat treatment completely reverted the $m$-phase content back to the $t$-phase; however, a higher resistance to transformation was observed for that scenario, even though there is no expected residual stress on that surface. Thus, the increased resistance to aging ( $t-m$ phase transformation) could be possibly related to the existence of this very thin layer of recrystallized tetragonal nano-grains $(10-20 \mathrm{~nm})$, which were generated by grinding, whose size are smaller than the critical size for transformation in a humid environment (25).

Even with the limitations of this in vitro study, our data clearly supports the benefit of polishing the Y-TZP ceramic after this material has been ground, instead of glazing and heat treatment. However, we did not consider an association of factors, such as grinding followed by polishing and heat treatment, thus more studies are recommended. Additionally, no intermittent mechanical loading or fatigue were conducted - since dental restorations are known to fail due to fatigue effects, where cyclic forces below the characteristic strength of the material act on existing defects, resulting in the progressive growth of these defects until they achieve a critical size where a fracture occurs (slow crack growth).

When taking into account the mechanical outcomes, it can be concluded that polishing of ground zirconia surfaces improves the mechanical behavior, thus polishing is the most appropriate surface treatment to be performed after grinding Y-TZP ceramics.

\section{Resumo}

Este estudo avaliou o efeito do envelhecimento através da degradação a baixas temperaturas (low temperaturare degradation - LTD) após a realização de tratamentos de superfície pós- sinterização (poPPnento, tratamento térmico e glaze) nas características superficiais (micromorfologia e rugosidade), e na estabilidade estrutural (transformação de fase e comportamento mecânico - resistência flexural e confiabilidade estrutural) de uma cerâmica de zircônia tetragonal policristalina estabilizada por itria (Y-TZP) desgastada. Discos de cerâmica Y-TZP (VITA In-Ceram YZ) foram confeccionados (ISO:6872-2015; 15mm de diâmetro e 1,2 \pm 0,2 mm de espessura) e randomicamente divididos em 10 grupos de acordo com dois fatores: "envelhecimento" (com e sem) e "tratamento de superfície" (Ctrl sem tratamento; $\mathrm{Gr}$ - desgaste com ponta diamantada grossa; $\mathrm{Gr}+$ HT - desgaste mais tratamento térmico; $\mathrm{Gr}+\mathrm{Pol}$ - desgaste mais polimento; $\mathrm{Gr}+\mathrm{Gl}$ - desgaste mais glazeamento). Foram realizadas as análises de rugosidade $(n=30)$, flexão biaxial $(n=30)$, transformação de fase $(n=2)$ e topografia de superficie $(n=2)$. 0 envelhecimento levou a um aumento intenso no conteúdo de fase monoclínica $(\mathrm{m})$ em todas as condições testadas, sendo observada uma maior susceptibilidade de transformação de fase $t-m$ nas amostras do grupo controle $(C t r l=65.6 \%)$. Apesar de provocar elevada transformação de fase, o envelhecimento não apresentou efeitos negativos nos desfechos avaliados. Não houve redução significativa do módulo de Weibull após os tratamentos. Além disso, o tratamento térmico e o glaze após desgaste levaram a uma redução da resistência característica, enquanto que o grupo polimento apresentou o mais alto valor de resistência característica. 0 glaze e o tratamento térmico geraram o pior desempenho mecânico, portanto a realização do polimento após desgaste de uma cerâmica Y-TZP é obrigatória.

\section{Acknowledgements}

The authors state that there are no conflict of interests. We thank CAPES (Agency for the High-Standard Promotion of Graduate Courses) for supporting this study. In addition, we thank KG Sorensen for donating the diamond burs and VITA Zahn fabrik for the donation of ceramics.

\section{References}

1. Stawarczyk B, Keul C, Eichberger M, Figge D, Edelhoff D, Lumkemann $\mathrm{N}$. Three generations of zirconia: from veneered to monolithic. Part I. Quintessence Int. 2017;48:369-380.

2. Denry I, Kelly JR. Emerging ceramic-based materials for dentistry. J Dent Res. 2014;93:1235-1242.

3. Piconi C, Maccauro G. Zirconia As A Ceramic Biomaterial, A Review. Biomaterials 1999; 20:1-25.

4. Kobayashi K, Kuwajima H, Masaki T. Phase change and mechanical properties of ZrO2- Y203 solid electrolyte after ageing. Solid State lon. 1981;3-4:489-495.

5. Preis V, Grumser K, Schneider-Feyrer S, Behr M, Rosentritt M. The effectiveness of polishing kits: influence on surface roughness of zirconia. Int J Prosthodont. 2015;28:149- 51.

6. Pereira GKR, Silvestri T, Amaral M, Rippe MP, Kleverlaan CJ, Valandro LF. Fatigue limit of polycrystalline zirconium oxide ceramics: Effect of grinding and low-temperature aging. J Mech Behav Biomed Mater. 2016;61:45-54.

7. Pereira GKR, Fraga $S$, Montagner AF, Soares FZM, Kleverlaan CJ, Valandro LF. The effect of grinding on the mechanical behavior of Y-TZP ceramics: a systematic review and meta-analyses. J Mech Behav Biomed Mater. 2016;63:417-442.

8. Manjuran NG, Sreelal T. An in vitro study to identify a ceramic polishing protocol effecting smoothness superior to glazed surface. J Indian Prosthodont Soc. 2014;14:219- 27.

9. Guazzato M, Quach L, Albakry M, Swain MV. Influence of surface and heat treatments on the flexural strength of Y-TZP dental ceramic. J Dent. 2005;33:9-18.

10. ISO 6872. Dentistry - dental ceramics. Int. Organ. Stand. 2015.

11. Guilardi LF, Pereira GK, Gündel A, Rippe MP, Valandro LF. Surface micro-morphology, phase transformation, and mechanical reliability of ground and aged monolithic zirconia ceramic. J Mech Behav Biomed Mater. 2017;65:849-856.

12. Dutra DAM, Pereira GKR, Kantorski KZ, Exterkate RAM, Kleverlaan CJ, 
Valandro LF, et al., Grinding with diamond burs and hydrothermal aging of a Y-TZP material: effect on the material surface characteristics and bacterial adhesion. Oper Dent. 2017;42:669-678.

13. Garvie RC, Nicholson PS. Phase analysis in zirconia systems. J Am Ceram Soc1972;55:303-305.

14. Toraya $H$, Yoshimura $M$, Somiya S. Calibration curve for quantitative analysis of the monoclinic tetragonal ZrO2 system by X-rays diffraction. J Am Ceram Soc 1984;67:119- 121.

15. Kosmac T, Wagner R, Claussen N. X-Ray Determination of transformation depths in ceramics containing tetragonal ZrO2. J Amer Ceram Soc. 1981;64:c72-c73.

16. Quinn GD. NIST Recommended Practice Guide: Fractography of Ceramics and Glasses. Nat Inst Stand Technol, 2007.

17. Wachtman Jr JB, Capps W, Mandel J. Biaxial flexure tests of ceramic substrates. J Mater. 1972;7:188-194.

18. Weibull, W. A statistical distribution function of wide applicability. J Appl Mech 1951;18:293-297.

19. DIN ENV 843-5, 2007. Advanced technical ceramics - Monolithic ceramics; mechanical tests at room temperature - Part 5: statistical analysis. Dtsch. Inst. für Norm. - DIN.

20. Pereira GKR, Amaral M, Cesar PF, Bottino MC, Kleverlaan CJ, Valandro LF. Effect of low-temperature aging on the mechanical behavior of ground Y-TZP. J Mech Behav Biomed Mater. 2015;45:183-192.

21. Dutra DAM, Pereira GKR, Kantorski KZ, Valandro LF, Zanatta FB.
Does finishing na polishing of restorative materials affect bacterial adhesion and biofilm formation? A systematic review. Oper Dent. 2018;45:E37-E52.

22. Zucuni CP, Guilardi LF, Rippe MP, Pereira GKR, Valandro LF. Fatigue strength of yttria- stabilized zirconia polycrystals: effects of grinding, polishing, glazing and heat treatment. J Mech Behav Biomed Mater. 2017;75:512-520.

23. Whalen PJ, Reidinger F, Antrim RF. Prevention of low-temperature surface transformation by surface recrystallization in yttria-doped tetragonal zirconia. J Am Ceram Soc. 1989;72:319-21.

24. Muñoz-Tabares JA, Anglada M. Hydrothermal degradation of ground 3Y-TZP. J Eur Ceram Soc. 2012;32:325-333.

25. Muñoz-Tabares JA, Jiménes-Piqué $E$, Reyes-Gasga J, Anglada $M$. Microstructural changes in ground 3Y-TZP and their effect on mechanical properties. Acta Mater. 2011;59:6670- 83.

26. Pozzobon JL, Pereira GKR, Wandscher VF, Dorneles LS, Valandro LF. Mechanical behavior of yttria-stabilized tetragonal zirconia polycrystalline ceramic after different zirconia surface treatments. Mater Sci Eng C Mater Biol Appl. 2017;77:828-835.

Received January 17, 2018 Accepted March 27, 2018 